\title{
Economic Implications of Pathogen Reduced and Bacterially Tested Platelet Components: A US Hospital Budget Impact Model
}

\author{
Katherine M. Prioli ${ }^{1}$. Julie Katz Karp ${ }^{2}$ Nina M. Lyons ${ }^{3} \cdot$ Vera Chrebtow $^{4} \cdot$ Jay H. Herman $^{2} \cdot$ Laura T. Pizzi $^{1}$
}

Published online: 31 July 2018

(c) The Author(s) 2018

\begin{abstract}
Background US FDA draft guidance includes pathogen reduction (PR) or secondary rapid bacterial testing (RT) in its recommendations for mitigating risk of platelet component (PC) bacterial contamination. An interactive budget impact model was created for hospitals to use when considering these technologies.

Methods A Microsoft Excel model was built and populated with base-case costs and probabilities identified through literature search and a survey of US hospital transfusion service directors. Annual costs of PC acquisition, testing, wastage, dispensing/ transfusion, sepsis, shelf life, and reimbursement for a mid-sized hospital that purchases all of its PCs were compared for four scenarios: $100 \%$ conventional PCs (C-PC), 100\% RT-PC, 100\% PR-PC, and 50\% RT-PC/50\% PR-PC.

Results Annual total costs were US\$3.64, US\$3.67, and US\$3.96 million when all platelets were C-PC, RT-PC, or PR-PC, respectively, or US $\$ 3.81$ million in the 50\% RT-PC/50\% PR-PC scenario. The annual net cost of PR-PC, obtained by subtracting annual reimbursements from annual total costs, is $6.18 \%$ above that of RT-PC. Maximum usable shelf lives for C-PC, RT-PC, and PR-PC are 3.0, 5.0, and 3.6 days, respectively; hospitals obtain PR-PC components earliest at 1.37 days. Conclusion The model predicts minimal cost increase for PR-PC versus RT-PC, including cost offsets such as elimination of bacterial detection and irradiation, and reimbursement. Additional safety provided by PR, including risk mitigation of transfusion-transmission of a broad spectrum of viruses, parasites, and emerging pathogens, may justify this increase. Effective PC shelf life may increase with RT, but platelets can be available sooner with PR due to elimination of bacterial detection, depending on blood center logistics.
\end{abstract}

Laura T. Pizzi

laura.pizzi@rutgers.edu

Katherine M. Prioli

katherine.prioli@rutgers.edu

Julie Katz Karp

julie.karp@jefferson.edu

Nina M. Lyons

nlyons628@gmail.com

Vera Chrebtow

vchrebtow@cerus.com

Jay H. Herman

jay.herman@jefferson.edu

1 Center for Health Outcomes, Policy, and Economics, Rutgers University, 160 Frelinghuysen Road, Suite 417, Piscataway, NJ 08854, USA

2 Department of Pathology, Anatomy, and Cell Biology, Thomas Jefferson University Hospital, 111 South 11th Street, Philadelphia, PA 19107, USA

3 Thomas Jefferson University, 901 Walnut Street, Suite 901, Philadelphia, PA 19107, USA

4 Global Marketing and Communications, Cerus Corporation, 2550 Stanwell Drive, Concord, CA 94520, USA

\section{Key Points for Decision Makers}

Emerging technologies for mitigating the risk of bacterial contamination in platelets, including pathogen reduction and secondary rapid bacterial testing, must be evaluated by hospital transfusion service decision makers in terms of budget impact and shelf life considerations.

An interactive, customizable budget impact model allows hospitals to understand the comparative costs of these competing technologies.

Although pathogen-reduced platelets have slightly greater total annual costs than those tested with secondary rapid bacterial testing, they provide additional safety benefits and cost offsets not experienced by rapid-tested units. 


\section{Introduction}

Blood components and transfusions are critical to ensuring successful lifesaving and costly medical treatments and procedures, including surgeries, trauma care, chemotherapy, and stem cell and organ transplants. In the US, blood centers collect, process, and supply blood components to hospitals. Most hospitals purchase blood products from blood center suppliers and often supplement their supply through in-house collections. In 2013, approximately 14.2 million units of blood products were collected in the US, with 13.2 million transfused [1]. Of these components, approximately 2.28 million platelet units were transfused [1], predominantly for hematology and oncology patients $(34 \%)$, followed by surgery (18\%), general medicine (17\%), and intensive care units (12\%) [2]. Platelets present certain challenges due to their limited shelf life (5 days post-collection). They are highly susceptible to bacterial contamination due to room temperature storage, often resulting in septic reactions when contaminated units are transfused [3-8].

Screening for certain blood-borne pathogens has been implemented to improve blood safety. However, residual infectious risks still threaten patients, largely due to bacteria [3-8] and emerging pathogens [9-14]. Bacterial contamination is the leading infectious risk associated with platelet transfusion, occurring in approximately 1 in 1500 apheresis platelet components (PCs) [3-8]. Primary bacterial culture, a screening method used for almost all platelets in the US supply, fails to detect more than half of bacterial contaminations [3-8]. Furthermore, because no active system for adverse event reporting exists in the US, bacterial contamination of platelets and resulting sepsis are underrecognized and underreported [15, 16]. Recent publications suggest that the rate of transfusion-associated (TA) septic reactions determined via active reporting is approximately tenfold that identified by passive reporting [15]. In a 7-year multicenter study, Hong et al. reported a $1: 2500$ and $1: 10,288$ risk in bacterially contaminated and septic reactions, respectively, with active surveillance, when using platelets previously screened and found negative by bacterial culture [16]. However, despite improvements in detection through active reporting, the linkage between a contaminated platelet and sepsis remains difficult to confirm in clinical settings as patients receiving platelets are often medically complex with underlying issues that can predispose them to infection $[16,17]$.

Emerging pathogens, such as Zika, chikungunya, and dengue viruses, as well as Babesia, pose another risk to the blood supply [9-14]. Challenges to a reactive testing strategy arise during these outbreaks: test development and pursuant regulatory approvals may require several years to complete, and continual addition of tests becomes increasingly costly for blood centers and hospitals [18]. Even in the presence of testing, infectious outbreaks can adversely impact blood product availability [18].

The US FDA has historically published formal guidance documents to address risks pertaining to transfusion-transmitted infections (TTIs). In March 2016, the FDA published a draft guidance on platelet bacterial contamination mitigation to improve platelet safety through implementation of specific measures, including pathogen reduction (PR) and secondary rapid bacterial testing (RT) of platelets [3]. In addition, the FDA published a separate final guidance in August 2016 in response to the Zika virus outbreak, recommending the use of either PR or nucleic acid testing (NAT) prior to releasing all three blood components (platelets, red blood cells, plasma) for transfusion [9].

The INTERCEPT ${ }^{\circledR}$ Blood System (Cerus Corporation) is currently the only FDA-approved PR system for apheresis platelets. Viruses, bacteria, parasites, and white blood cells, including $\mathrm{T}$ cells, are inactivated during the PR process, thus reducing the risk for TTIs, including sepsis and TA graft-versus-host disease (TA-GVHD) [19]. PR of platelets replaces both primary and secondary bacterial detection, cytomegalovirus (CMV) serology testing, irradiation, and Zika NAT [3, 9, 19, 20].

Secondary RT is an alternate measure also included in the FDA draft guidance. The Pan Genera Detection (PGD) test (Verax Biomedical) is FDA-approved as a safety measure intended to identify bacterially contaminated platelet units within $24 \mathrm{~h}$ prior to transfusion, following primary testing with a bacterial culture [21]. The PGD test may confer a 7-day shelf life provided that certain criteria are met, including the use of blood bags approved for extended storage, and testing and re-labeling conducted by an FDA-registered blood product manufacturer (blood center or hospital).

The evolving regulatory landscape, driven by the FDA draft guidance, has influenced hospitals to consider interventions such as PR and bacterial testing to mitigate bacterial contamination of platelets. As such, the budgetary impact of these technologies must be evaluated by healthcare purchasers and providers. The objective of this study was to develop a budget impact model allowing hospitals to assess the financial implications of these bacterial contamination mitigation options in the context of the total blood bank budget.

\section{Methods}

\subsection{Model Overview}

An interactive model was developed using Visual Basic for Applications in Microsoft Excel (Microsoft Corporation, 
Redmond, WA, USA) to analyze the annual budget impact for different platelet types used for transfusion in hospitals.

The model takes the US hospital transfusion service perspective with a time horizon of 1 year, and costs evaluated in 2017 and 2018 US\$. Its framework reflects the personnel and variable material costs of the tasks and processes involved in platelet management from acquisition through transfusion, and septic adverse events. This framework was prepopulated with modifiable base-case costs and probabilities identified through a survey administered to 27 hospital transfusion service directors [22] (Fig. 1, Table 1), a literature search, and two hospital transfusion service site visits. The literature search served to fill in model assumptions not obtained via the survey, and consisted of a series of targeted PubMed searches using keywords specific to the model variables of interest and focused on English-language articles no earlier than 2005 (a 10-year look-back period at the time of the literature search). Costs and probabilities resulting from the literature search were reviewed with transfusion medicine experts (JKK and JHH) to determine their reliability based on the experts' judgment. For those model assumptions for which several values were available in the literature, a weighted average was taken of those judged as reliable by the experts. The model structure and assumptions were refined following review by an independent panel of seven US transfusion medicine physicians, including all assumptions obtained by literature search.

Because platelet processes vary by institution, the model was structured such that initial inputs gathered at the beginning of the model are used to adaptively route the end user through the model, ensuring that only those aspects relevant
Table 1 Number of hospital beds and number of platelets dispensed per month for the facilities participating in the survey

\begin{tabular}{lll}
\hline & $\begin{array}{l}\text { No. of hospital } \\
\text { beds }[n=27]\end{array}$ & $\begin{array}{l}\text { No. of platelet units } \\
\text { dispensed per month } \\
{[n=26]}\end{array}$ \\
\hline Mean & 638.2 & 489.5 \\
Standard deviation & 307.2 & 535.2 \\
Minimum & 196 & 40 \\
Maximum & 1157 & 2500 \\
\hline
\end{tabular}

to the user's institution are included (Fig. 2). These initial inputs include platelet acquisition source (purchased from an external vendor, produced in-house, or a combination) and use of RT, with or without extending to a 7-day shelf life. If the user's institution does not produce platelets via in-house collection, the user will not be routed through the 'Production' module, and, similarly, if the user's institution does not use RT, the user will not pass through the 'Secondary Bacterial Testing' module, nor will a 7-day shelf life be considered. Cost and probability variables in the model include platelet acquisition costs, tests performed, and associated costs, wastage rates, and whether the hospital purchases or produces its own platelets. In this paper, we present four model scenarios enabling comparison of annual hospital costs of platelet acquisition, testing, wastage, dispensing and transfusion, as well as shelf life and reimbursement impacts, for a facility that purchases all of its platelets. The four scenarios are: (1) 100\% conventional PCs (C-PC) prescreened using bacterial culture that undergo neither RT nor PR; (2) $100 \%$ platelets screened with RT in addition to

Fig. 1 Facility types surveyed $(n=27)$, number of hospitals and relative proportion (\%). Although the number of subjects interviewed was 27 , some had multiple responses as there was overlap with regard to institution types. VA Veterans' Administration, Gov't government

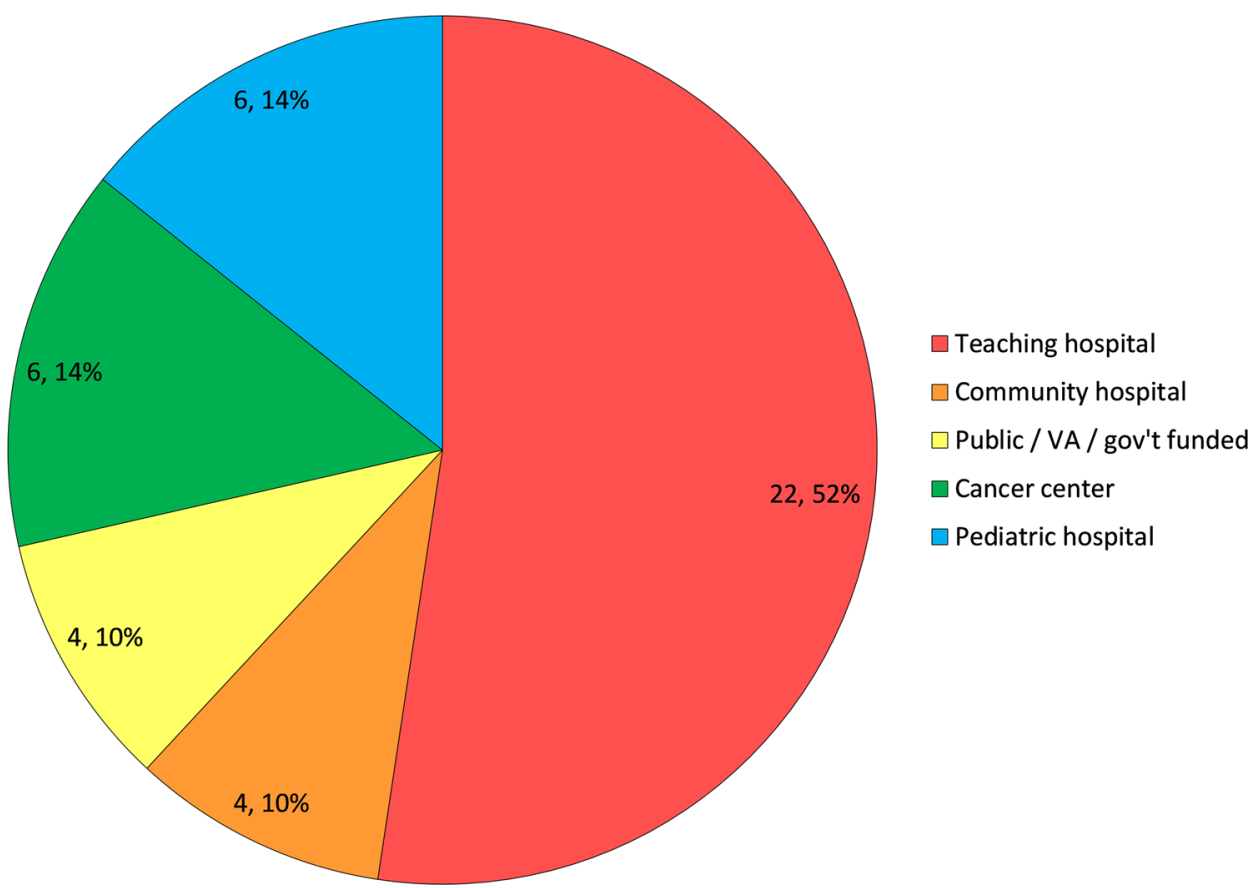




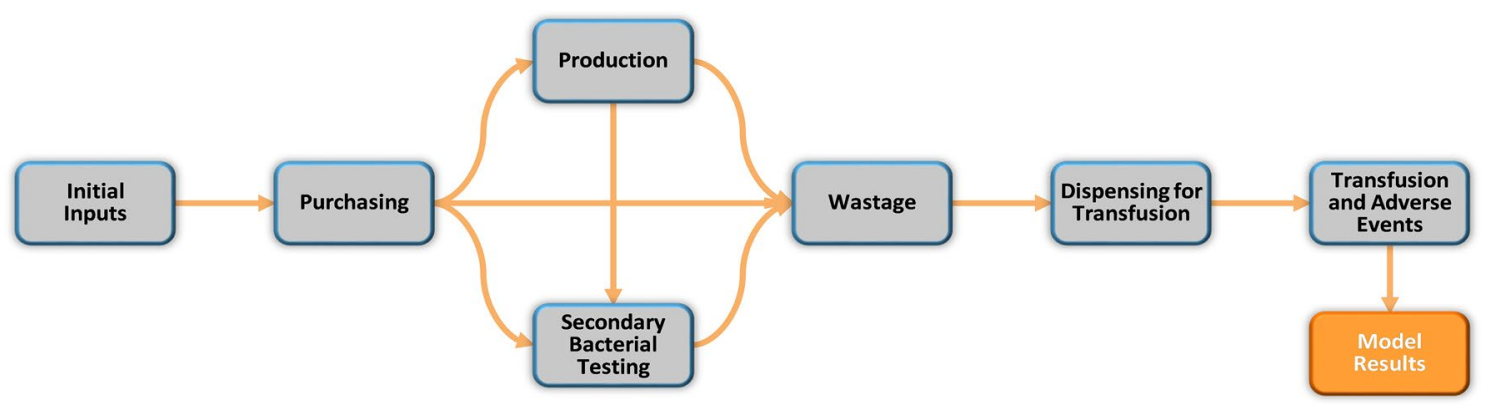

Fig. 2 Model framework

prescreening, with extended shelf life to 7 days (RT-PC); (3) $100 \%$ pathogen-reduced platelets (PR-PC) without bacterial prescreening, with a shelf life of 5 days; and (4) a combined inventory of RT-PC and PR-PC (50/50\%). These scenarios were selected to represent the extreme cases (e.g. $100 \%$ inventory per technology), as supported by the FDA draft guidance [3], and a combination thereof to represent institutions that decided to implement both technologies.

\subsection{Model Assumptions}

\subsubsection{Personnel Costs}

Based on survey results and input from transfusion medicine experts (JKK and JHH) and the independent review panel, most tasks in the model are assumed to be performed by a hospital Blood Bank Technician or Technologist, with a base-case wage rate of US\$24.91/h [23], based on the mean hourly wage rate for a Blood Bank Technician/Technologist per the Bureau of Labor Statistics (BLS), and a fringe benefits rate of $34.3 \%$ per BLS [24]. Per our prior research [25], select transfusion-related tasks are assumed to be performed by a nurse (e.g. performing and monitoring transfusion) or physician (e.g. placing an order for platelets and consenting the patient), with base-case wage rates of US\$34.14 and US\$95.05, respectively.

\subsubsection{Platelet Acquisition}

A mid-sized hospital that acquires 5500 apheresis PCs per year purchased from an external blood center supplier is assessed in each scenario. For both scenario 1 (C-PC) and scenario 2 (RT-PC), it is assumed that $60.7 \%$ of acquired platelets are irradiated and $20 \%$ are tested for CMV by the blood center supplier, with the remaining undergoing neither irradiation nor CMV testing [26]. Hospital acquisition cost assumptions are detailed in Table 2. For conventional units, the acquisition price is based on the price of a conventional platelet as reported in the National Blood Collection and Utilization in the United States (NBCUS) report [43]. For
Table 2 Platelet acquisition costs for different platelet component types used in the model

\begin{tabular}{ll}
\hline Apheresis platelet component type & $\begin{array}{l}\text { Acquisition price per } \\
\text { component (US\$) }\end{array}$ \\
\hline Conventional (non-pathogen-reduced) & 525.00 \\
CMV-negative (serology tested) & 570.00 \\
Irradiated & 600.00 \\
Pathogen-reduced & 640.00
\end{tabular}

$C M V$ cytomegalovirus

CMV-negative units, the acquisition price is the NBCUS conventional price scaled up by $9.5 \%$ to account for the realworld upcharge for CMV-negative units based on authors' estimates. For irradiated units, the acquisition price is the NBCUS conventional price scaled up by $15 \%$ to account for the upcharge for irradiation based on authors' estimates. Finally, for pathogen-reduced units, the acquisition price is based on the NBCUS price for a conventional unit plus $\$ 115$, which is the authors' estimated upcharge for pathogenreduced units. All prices were rounded to the nearest $\$ 5$ for convenience.

\subsubsection{Platelet Testing}

For RT-PC, it is assumed that primary culture-based testing and RT occur at the blood center and hospital, respectively, consistent with common practice at hospitals that purchase their platelet stock and perform RT. RT starts on day 4, with one test performed per unit, per day, for platelets $\geq 4$ days of age [3]. Platelet units that test positive by RT are retested two more times, as instructed in the platelet PGD test package insert [21]. Per-test material and personnel costs of RT are assumed to be US\$25 and US\$5.57, respectively [23, 24, 27].

The model assumes that PR, which occurs at the blood center supplier, replaces bacterial detection (primary and secondary), CMV serology, irradiation, and Zika testing [3, 9, 19, 20]. For RT-PC, the blood supplier's cost for Zika 
testing (US\$7.50/unit) is passed on to the hospital in the purchase price; PR-PC units do not require Zika testing.

\subsubsection{Platelet Distribution and Wastage}

Since PR-PC are not required to undergo primary bacterial culture, the release timing of PR-PC depends on the availability of required NAT results, thus shelf life is gained through earlier release to the hospital than RT-PC. In contrast, RT-PC still require primary bacterial culture, which, as modeled here, entails an initial 24-h hold post-sampling, followed by an additional 12-h hold to monitor for bacterial growth prior to release (Fig. 3); thus, release of RT-PC occurs on day 2. For both PR-PC and RT-PC, an NAT turnaround time of $24 \mathrm{~h}$ from platelet collection to receipt of result is assumed; this is the mean value obtained (range 12-38 h) per survey results [22]. The upfront increase in effective shelf life for PR-PC over RT-PC (12 h) is the differential between time saved by avoiding primary bacterial culture and assumed NAT result availability.

Wastage is defined as units that must be discarded due to the lack of usability. The model assumes that, for C-PC, six units are wasted weekly, and that this wastage is attributable to unit expiration (68.3\%) and unit mishandling (31.7\%); these values represent the mean values reported in the survey [22]. Wastage costs include the cost of wasted units (a weighted average based on the product mix specified under Sect. 2.2.2) and the staff time for documenting and disposing of each wasted unit (7.8 min of Blood Bank Technician or Technologist time for each wasted unit per survey results).
For PR-PC units, wastage costs are calculated similarly to C-PC, but are based on a $100 \%$ PR-PC inventory, and the wastage due to expiration is adjusted downward by $1.6 \%$ for every hour of shelf-life gained [27-29]. Since $15 \mathrm{~h}$ of shelf life are gained with PR-PC, the reduction in wastage cost of PR-PC is attributable to time gained upfront due to avoidance of primary bacterial culture, and the overall 5-day expiry as per currently approved FDA labeling.

The model also assumes that RT-PC require both primary bacterial culture and RT, based on the requirements outlined in the FDA draft guidance and PGD package insert. Wastage calculations are based on the assumptions that RT-PC are not released to the hospital until day 2 (i.e. after primary culture testing), thus yielding an effective shelf life of 5 days. The reduction of wastage cost in RT-PC is attributable to the $48 \mathrm{~h}$ of shelf life that are gained with RT-PC compared with C-PC. Wastage costs for RT-PC are calculated similarly to $\mathrm{C}-\mathrm{PC}$, but wastage due to expiration is adjusted downward by $1.6 \%$ for each hour of shelf-life gained, and the material and personnel costs of RT are included. Platelet wastage due to false positive RT results is also considered. Published false positive rates of 0.91 and $0.51 \%$ for initial and repeat false positive rates, respectively, are used in the calculation [21].

\subsubsection{Platelet Dispensing for Transfusion}

This model assumes all tasks for the dispensation of platelets for transfusion are performed by a hospital Blood Bank Technician/Technologist, with the exception of platelet ordering (performed by the floor physician) and delivery of platelets to the floor (via pneumatic tube) [25].

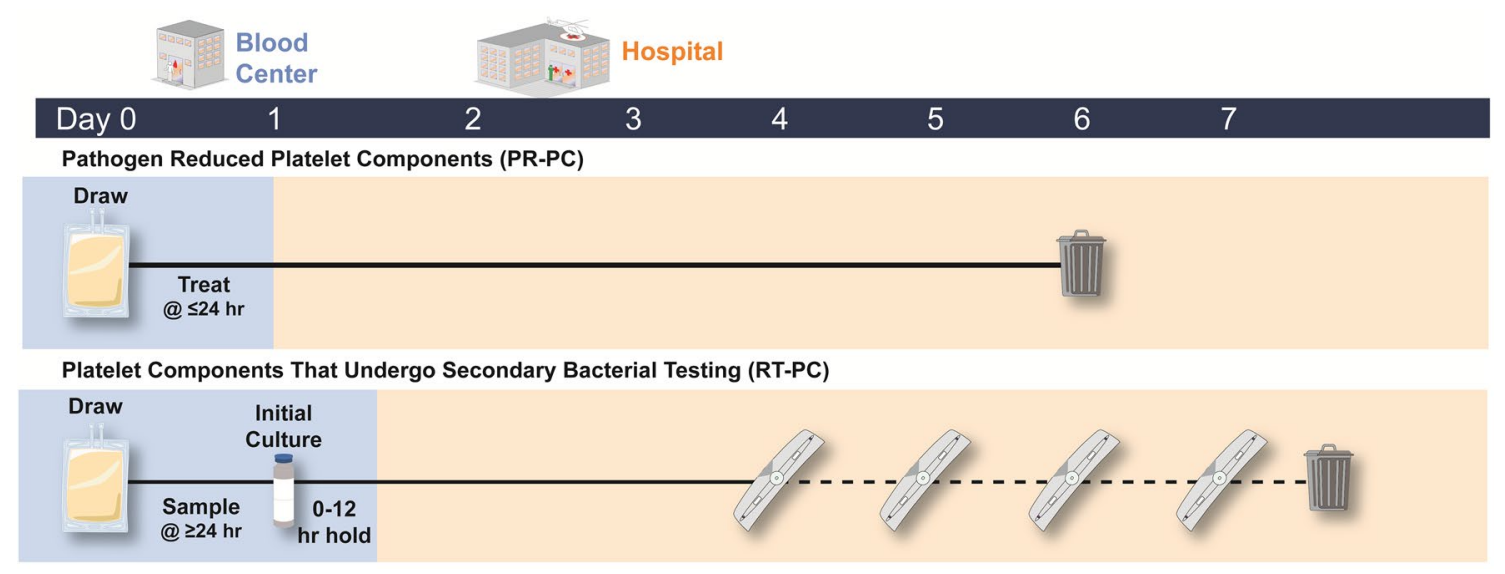

Fig. 3 Comparative shelf life of PR-PC versus RT-PC. Time to release to the hospital (blue shading) is determined by NAT turnaround time and initial culture time. PR-PC have a 24-h time to release, all due to NAT turnaround time, whereas RT-PC have a 36-h turnaround time due to both NAT $(24 \mathrm{~h})$ and initial bacterial testing and associated hold time (additional $12 \mathrm{~h}$ ). PR-PC have an over- all 5-day shelf life, and RT-PC are extended to a 7-day shelf life in this model, and require four secondary rapid bacterial tests (one per day of shelf life starting on day 4 , represented by symbols along the dashed line). NAT nucleic acid testing, $P R-P C$ pathogen-reduced platelet component, $R T-P C$ rapid-tested platelet component 


\subsubsection{Sepsis Transfusion Reaction Rate and Associated Costs}

The continued risks for septic transfusion reactions with conventional platelets have been demonstrated in a recently published multicenter study [16]. For C-PC and RT-PC, our model assumes a sepsis probability of 0.0000972 per Hong et al., who found that 1 in 10,288 platelet units were retrospectively implicated in septic transfusion reactions, but missed via passive surveillance. For PR-PC, our model assumes that the probability of sepsis is zero based on data collected via national hemovigilance programs that track routine use of pathogen-reduced platelets [31-33].

Treatment costs, number of units transfused, and the probability of sepsis are considered when calculating annual sepsis costs. The mean treatment cost assumed by the model is US $\$ 13,714$ per non-fatal sepsis case, as derived from the Healthcare Cost and Utilization Project (HCUP) 2014 database for the International Classification of Diseases, Ninth Revision (ICD-9) code 995.91, corresponding to sepsis without organ dysfunction [30], and inflated to 2015 US\$ using the Consumer Price Index for medical cost inflation. Costs and legal settlements for severe, septic shock, and fatal sepsis cases were not included in this model.

\subsubsection{Reimbursement}

The model incorporates payment rates for RT-PC and PR-PC per the Centers for Medicare and Medicaid Services (CMS) Healthcare Common Procedure Coding System (HCPCS) Level II codeset, which is used by hospitals for billing products transfused in the outpatient setting (Table 3) [34]. In the model, for platelet units undergoing RT, the reimbursement amount is only counted once, regardless of the number of RTs a given unit may have undergone. For all units, reimbursement only applies to those platelet units transfused in the outpatient setting; units transfused in the inpatient setting are not reimbursed separately from the DRG-based payment rates. In the scenarios analyzed, $26 \%$ of transfusions were assumed to be performed in the outpatient setting [26], and that all platelets transfused in the outpatient setting, regardless of payer, are reimbursed at the CMS payment rate for CY2018.

\section{Results}

\subsection{Annual Costs and Outpatient Reimbursement}

For this example hospital, the annual total cost of platelet products and their use was US\$3.64, US\$3.67, and US\$3.96 million when all platelets are C-PC, RT-PC, or PR-PC, respectively. A hospital that has an evenly mixed inventory of RT-PC and PR-PC would have an annual cost of US\$3.81 million (Table 4). When accounting for outpatient reimbursement, net annual costs are US\$2.75, US\$2.75, and US $\$ 2.92$ million for $100 \%$ C-PC, 100\% RT-PC, and 100\% $\mathrm{PR}-\mathrm{PC}$, respectively; there is a small annual net cost increase of $6.18 \%$ when comparing PR-PC with RT-PC.

Differences in annual costs are largely driven by platelet acquisition, wastage due to expiration, and RT- and sepsis-related costs. Acquisition costs were slightly greater for PR-PC due to a higher purchase price (an additional US\$61 per PR-PC unit) versus the blended acquisition cost for $60 \%$ of RT-PC that undergo irradiation, $20 \%$ of RT-PC that undergo CMV testing, and the remainder of RT-PC without irradiation or CMV testing. [Blended cost of RT-PC is US\$579 ([US\$600 $\times 0.6]+[\mathrm{US} \$ 570 \times$ $0.2]+[$ US $\$ 525 \times 0.20]$ ), thus PR-PC upcharge becomes US $\$ 640$ - US $\$ 579=\mathrm{US} \$ 61]$. This upcharge is partially offset by costs avoided with PR-PC, including RT, irradiation, CMV serology testing, and Zika testing. The cost of wastage due to expiration was US\$81,079 greater for PR-PC versus RT-PC, which reflects the differential in allowable platelet shelf life for each platelet type (5- and 7-day, respectively). Conversely, RT and sepsis-related costs are greater for RT-PC than for PR-PC. RT costs totaled US\$121,890, including the costs of false positive results. Estimated RT-PC sepsis treatment costs were US\$7289. Both RT and

Table 3 CMS outpatient reimbursement rates for platelet components

\begin{tabular}{llc}
\hline HCPCS code & Platelet type & $\begin{array}{c}\text { CMS OPPS per unit } \\
\text { payment rate (2018 } \\
\text { US\$) }\end{array}$ \\
\hline P9035 & Platelets, pheresis, leukocytes reduced, each unit & 476.96 \\
P9055 & Platelets, leukocytes reduced, CMV-negative, apheresis/pheresis, each unit & 339.93 \\
P9037 & Platelets, pheresis, leukocytes reduced, irradiated, each unit & 624.61 \\
P9053 & Platelets, pheresis, leukocytes reduced, CMV-negative, irradiated, each unit & 539.80 \\
P9073 & Platelets, pheresis, pathogen-reduced, each unit & 624.61 \\
P9100 & Pathogen(s) test for platelets & 25.50 \\
\hline
\end{tabular}

HCPCS Healthcare Common Procedure Coding System, CMS Centers for Medicare and Medicaid Services, OPPS Outpatient Prospective Payment System, $C M V$ cytomegalovirus 
Table 4 Annual platelet costs, reimbursement, and shelf life

\begin{tabular}{|c|c|c|c|c|}
\hline & $100 \%$ C-PC (US\$) & $100 \%$ RT-PC (US\$) & $100 \%$ PR-PC (US\$) & $\begin{array}{l}50 \% \\
\text { RT-PC/50\% } \\
\text { PR-PC (US\$) }\end{array}$ \\
\hline Acquisition & $3,192,540$ & $3,192,540$ & $3,527,680$ & $3,360,110$ \\
\hline RT costs & 0 & 121,890 & 0 & 60,945 \\
\hline Wastage & 182,067 & 86,565 & 167,644 & 127,104 \\
\hline Dispensing/transfusion & 260,721 & 260,721 & 260,721 & 260,721 \\
\hline $\begin{array}{l}\text { Sepsis (excludes septic shock cases that result } \\
\text { in MODs/mortality/morbidity) }\end{array}$ & 7289 & 7289 & 0 & 3645 \\
\hline Total annual cost & $3,642,617$ & $3,669,005$ & $3,956,045$ & $3,812,525$ \\
\hline Outpatient reimbursement & 895,238 & 922,347 & $1,037,508$ & 979,927 \\
\hline Total hospital cost (less reimbursement) & $2,747,379$ & $2,746,658$ & $2,918,537$ & $2,832,598$ \\
\hline Percentage of blood budget ${ }^{a}$ & 2.11 & 2.11 & 2.24 & 2.18 \\
\hline PC age when placed in inventory (h) & 48 & 48 & 33 & NA \\
\hline Maximum usable shelf life (h) & 72 & 120 & 87 & NA \\
\hline
\end{tabular}

${ }^{a}$ Assumes an annual blood budget of US\$130 million, including platelet, plasma, and red blood cell components

$C-P C$ conventional platelet component, $R T-P C$ rapid-tested platelet component, $P R-P C$ pathogen-reduced platelet component, $R T$ rapid testing, $M O D$ s multiple organ dysfunction syndrome, $P C$ platelet component, $N A$ not applicable

sepsis-related costs, which total US\$129,179, are avoided with the use of PR-PC.

\subsection{Platelet Shelf Life and Expiry}

Maximum usable platelet shelf life is calculated as the difference between the maximum approved shelf life and the mean age when PCs are placed into inventory. The maximum usable shelf life for RT-PC is $120 \mathrm{~h}$ (5 days), assuming that the hospital receives such components on day 2 (Table 4). Conversely, C-PC and PR-PC currently have an overall 5-day expiration. Maximum usable shelf life is calculated at $75 \mathrm{~h}$ (3 days) and $87.2 \mathrm{~h}$ (3.63 days) for C-PC and PR-PC, respectively; hospitals obtain PR-PC earlier than C-PC and RT-PC at 1.37 days (Table 4). For PR-PC, early release of the platelet unit is driven by elimination of primary bacterial culture at the blood center supplier; thus, the turnaround time for NAT results, rather than the PR process, is the limiting factor to platelet release.

\section{Discussion}

We present an economic model to aid in hospital transfusion service decision making when evaluating new technologies for platelet preparation and/or new testing regimens. The recent introduction of new products such as pathogenreduced platelets has provided the opportunity for hospital blood banks to assess the clinical and financial impact of such innovative advances. Our findings are particularly timely given the anticipated release of final FDA guidance on platelet contaminant mitigation.
The model demonstrates a small net annual cost increase $(6.18 \%)$ for PR-PC compared with RT-PC. The primary factors driving this cost differential are the acquisition prices of the different PCs, their effective shelf lives, and related platelet wastage rates.

We assumed a greater acquisition price for PR-PC than RT-PC. The higher acquisition price may be justified by clinical benefits from inactivation of bacteria, viruses, protozoa, and T cells [19]. Costs that may accrue due to complications of viral and/or protozoan TTIs and TAGVHD are not included in this model. Nonetheless, such clinical implications and their potential cost impact should be considered in the context of overall blood safety when evaluating different technologies.

As examined in the model, shelf life is an important concept, both in terms of hospital supply management and cost impact. The PGD test is currently the only secondary rapid bacterial test approved as a safety measure by the FDA and may be used to extend platelet dating to 7 days for platelets suspended in $100 \%$ plasma. However, certain criteria must be met to extend shelf life, including the use of FDA-cleared 7-day platelet storage containers, potential modification of contractual agreements with outside suppliers to assure platelets are supplied with cleared storage containers, a new or updated FDA registration and blood product listing, new standard operating procedures to accommodate platelet testing, and relabeling every $24 \mathrm{~h}$ [35]. This model did not include these overhead costs that a hospital may accrue when implementing 7-day platelets with secondary testing; however, it did estimate the extended shelf life and associated savings due to reduced wastage with 7-day RT-PC. 
In contrast, pathogen-reduced platelets are approved for a 5-day shelf life, with no further testing or processing required by the hospital. Shelf life can be gained at the front end, allowing hospitals to receive younger platelets, depending on the turnaround time for the blood center supplier's NAT; NAT is required despite implementation of PR, such as for HIV and HCV for which an FDA mandate exists. If NAT results are available within $12 \mathrm{~h}$ of collection, blood center suppliers can release units within the first or second day of platelet collection, preserving approximately 3-4 days of effective shelf life. This model assumes a conservative turnaround time estimate of $24 \mathrm{~h}$ for NAT results, with a 5-day shelf life for pathogen-reduced units.

In addition to acquisition and wastage costs, RT and sepsis-related costs were evaluated. RT costs include material and personnel costs of all routine secondary rapid bacterial tests, as well as those performed due to false positive results (per PGD package insert, two additional confirmatory tests are required for every positive result). In addition, PGD test results are valid for no more than $24 \mathrm{~h}$ prior to transfusion. In order to minimize costs but comply with this labeling, some hospital transfusion services may opt to quarantine platelets and not test until such time that a transfusion is required. However, other hospitals may prefer to avoid the risks involved in releasing an untested quarantined unit for transfusion, or encountering an emergency situation with no tested product available for immediate transfusion. For example, Level 1 trauma centers generally require immediate availability of platelets and would therefore likely need to have units with valid PGD test results readily available (tested $\leq 24 \mathrm{~h}$ prior to transfusion), which will likely increase the need for retesting [36].

In another recent economic analysis [37], the cost of implementing PGD is estimated to be approximately US\$738 per unit, or US\$3.69 million per year for 5000 units, which is comparable to the annual costs estimated by our model. In the same study, PR-PC cost estimates are much higher than ours, largely driven by the assumption that patients receiving pathogen-reduced platelets require more frequent transfusions. However, increased utilization of pathogen-reduced platelets is not observed in routine use. Amato et al. report no increase in platelet or red blood cell utilization when comparing conventional versus pathogenreduced platelets after the implementation of PR [38]. Multiyear hemovigilance programs with routine transfusions of over 400,000 pathogen-reduced PCs have also demonstrated no increase in platelet utilization $[31,32,39]$. The same experience has been reported in the US by Mendez et al. [40], demonstrating that utilization of the platelet and red cell components is comparable between C-PC and PR-PC.

Finally, sepsis cost assumptions in the model are quite conservative. The cost to treat non-lethal sepsis ranges widely in published reports, largely due to varying sepsis definitions and treatment protocols, and the fact that sepsis is often accompanied by comorbidities such as pneumonia. As such, there is no widely accepted approach to assessing sepsis costs [41]. In this model, we queried the HCUP database for ICD-9 code 995.91 to obtain the mean cost per sepsis case of US\$13,714 (per US\$2014) [30]. This cost is considerably lower than those reported for more severe stages of sepsis in which greater length of stay and treatment is required. For example, mean costs based on hospital reimbursement have been reported at US\$39,736 and US\$51,307 for severe sepsis and septic shock, respectively [42]. Although difficult to quantify, there have been cases where deaths implicated with sepsis have led to legal disputes and settlements costing millions of dollars [43]. Overall, while acquisition and wastage costs were lower for RT-PC than for PR-PC, RT- and sepsis-associated costs are avoided for PR-PC.

The landscape of transfusion safety and bacterial contamination mitigation continues to evolve. In November 2017, the FDA's Blood Products Advisory Committee (BPAC) discussed additional safety options and recommended that these options be added to a future revised FDA draft guidance [44]. In addition to PR-PC and RT-PC options already included in the FDA draft guidance, the BPAC recommended two options that entail the use of large-volume bacterial culture. Similar to RT, such methods would only mitigate risk due to bacteria (not viruses, protozoa, or T cells). As with RT-PC, the use of secondary or delayed culture may enable centers to extend shelf life to 7 days; however, due to extensive upfront product hold time requirements, the maximum effective shelf life may only be approximately 4 days.

In summary, our model anticipates a small increase in cost with the adoption of PR-PC when compared with RT-PC. This can be partially offset by outpatient reimbursement. Assuming an overall total annual hospital blood budget of US\$130 million that includes platelet (5500 per year), plasma (15,000 per year), and red cell components (40,000 per year), and the associated costs of transfusion, the use of PR-PC represents a $0.13 \%$ increase in the overall annual blood products budget when compared with the use of RT-PC. The increase may be justified by the mitigation of TTIs due to viruses, protozoans (as well as bacteria), TAGVHD, and the avoidance of implementing new tests that require process changes and staff training.

\section{Limitations}

Our findings are limited by the scenarios we chose to model. First, we assumed the hospital purchases all of its platelets for transfusion, and did not examine a 'self-collector' case in which the hospital collects and manufactures platelets on site. Costs will vary in the self-collection case as 
self-collectors tend to perform procedures such as irradiation in-house and therefore may not pay a premium for irradiated PC. Furthermore, only apheresis platelets, which comprise approximately $90 \%$ of platelet transfusions in the US [45], are assumed in this model; whole blood-derived platelets are not considered.

Costs not considered for RT include costs of the durable equipment required to perform the test; only regular operating costs are considered. Other costs not included are potential FDA registration costs, as well as those attributed to the potential complexity in labeling and relabeling units to extend platelet dating to 7 days. Costs associated with recall, disposal of split units, and notification of the blood center for units that test positive via RT were also not considered. For pathogen-reduced components, all processing occurs at the supplier site; the hospital receives the finished transfusion-ready platelet product, thus incurring no capital equipment costs.

Lastly, costs that may accrue due to complications of viral and/or protozoan TTIs, TA-GVHD, and severe and/or lethal sepsis cases are not included in this model. Nonetheless, hospitals may wish to consider such clinical implications and potential cost impact in the context of overall blood safety when evaluating different technologies.

\section{Conclusions}

This model predicts a small (6.18\%) cost increase for PR-PC compared with RT-PC, which includes cost offsets such as elimination of bacterial detection and irradiation, and reimbursement. In an annual overall hospital blood budget, PR-PC only represents a $0.13 \%$ increase in budget versus RT-PC. This minimal increase may be justified by additional safety provided by PR, which helps mitigate transfusiontransmission of viruses, parasites and emerging pathogens, and potentially TA-GVHD. PR also provides the benefit of not having to perform additional testing within the hospital. The effective PC shelf life is potentially increased with RT, but platelets may be available to the hospital sooner with PR due to the elimination of bacterial detection. Overall, given the evolving FDA guidance, such models are needed to inform hospital decision makers about the budgetary and process impacts of adopting these technologies to ensure the safety of the blood supply.

Acknowledgements The authors wish to acknowledge the following individuals for their contribution to this project: Patricia Kopko, M.D.; Meredith Reyes, M.D.; Neil Shah, M.D.; Joseph Sweeney, M.D.; and Aaron Tobian, M.D., Ph.D.

Author contributions KMP participated in all aspects of drafting, revision, and final review of the manuscript; provided editorial review, with focus on the Sects. 2 and 3 sections; and oversaw submission to the journal. JKK provided editorial review of the manuscript with focus on blood banking aspects. NML provided editorial review of the manuscript with focus on the Sects. 1 and 2. VC participated in all aspects of drafting, revision, and final review of the manuscript, and provided editorial review with focus on the Sects. 1 and 4. JHH provided editorial review of the manuscript with focus on blood banking aspects. LTP guided manuscript development and provided editorial review of the manuscript with focus on the economic modeling aspects.

\section{Compliance with Ethical Standards}

Data availability statement The transfusion service survey dataset generated and analyzed during the current study is not publicly available because hospital respondents were assured of confidentiality, and responses, even when anonymized, could be used to identify respondents. Aggregated survey results are available from the corresponding author upon reasonable request. The model generated during the current study is not publicly available because it is exclusively licensed by Cerus Corporation, but hospitals and/or interested readers can arrange a personalized demonstration of the model through Ms. Chrebtow (vchrebtow@cerus.com) upon reasonable request.

Conflict of interest Ms. Chrebtow is employed by Cerus Corporation, and Dr. Pizzi and Ms. Prioli have served as consultants to Cerus Corporation. Vera Chrebtow and Laura T. Pizzi: CERUS Corporation's sponsorship of the project to Rutgers University covered model development and reporting. Katherine M. Prioli has no major conflicts of interest to declare, however she received a modest honorarium and travel expenses for presenting model results at the Society for the Advancement of Blood Management (SABM) 2017 annual conference. Dr. Karp, Dr. Herman, and Dr. Lyons have no conflicts of interest to declare.

Funding This work was supported by a Grant from Cerus Corporation.

Ethics approval and informed consent As this study involves model construction and does not constitute human subjects research, it was granted exemption from Institutional Review Board (IRB) review. For the assumptions that were informed by a survey fielded to hospital transfusion service directors, the survey was preceded by text informing respondents of the purpose of the study and contact information for the Principal Investigator. IRB review and formal informed consent for this survey were not required because the survey questions pertained to institutional practices and did not include any respondent- or patientspecific information.

Open Access This article is distributed under the terms of the Creative Commons Attribution-NonCommercial 4.0 International License (http://creativecommons.org/licenses/by-nc/4.0/), which permits any noncommercial use, distribution, and reproduction in any medium, provided you give appropriate credit to the original author(s) and the source, provide a link to the Creative Commons license, and indicate if changes were made.

\section{References}

1. Chung KW, Basavaraju SV, Mu Y, van Santen KL, Haass KA, Henry R, et al. Declining blood collection and utilization in the United States. Transfusion. 2016;56:2184-92. 
2. Mulcahy AW, Kapinos KA, Briscombe B, Uscher-Pines L, Chaturvedi R, Case SR, et al. Toward a sustainable blood supply in the United States: an analysis of the current system and alternatives for the future. Santa Monica: RAND Corporation; 2016.

3. Bacterial risk control strategies for blood collection establishments and transfusion services to enhance the safety and availability of platelets for transfusion. FDA draft guidance for industry, March 2016. https://www.fda.gov/downloads/biologicsbloodv accines/guidancecomplianceregulatoryinformation/guidances/ blood/ucm425952.pdf. Accessed 17 Feb 2017.

4. Kleinman S, Reed W, Stassinopoulos A. A patient-oriented risk-benefit analysis of pathogen-inactivated blood components: application to apheresis platelets in the United States. Transfusion. 2013;53:1603-18.

5. Dumont LJ, Kleinman S, Murphy JR, Lippincott R, Schuyler $\mathrm{R}$, Houghton J, et al. Screening of single-donor apheresis platelets for bacterial contamination: the PASSPORT study results. Transfusion. 2010;50:589-99.

6. Murphy WG, Foley M, Doherty C, Tierney G, Kinsella A, Salami A, et al. Screening platelet concentrates for bacterial contamination: low numbers of bacteria and slow growth in contaminated units mandate an alternative approach to product safety. Vox Sang. 2008;95:13-9.

7. Pearce S, Rowe GP, Field SP. Screening of platelets for bacterial contamination at the Welsh blood service. Transfus Med. 2011;21:25-32

8. Walther-Wenke G, Wirsing von Konig CH, Daubener W, Heiden M, Hoch J, Hornei B, Volkers P, Working Party on Bacteria Safety in Transfusion Medicine ABotGMoHB. Monitoring bacterial contamination of blood components in Germany: effect of contamination reduction measures. Vox Sang. 2011;100:359-66

9. Recommendations for donor screening, deferral, and product management to reduce the risk of transfusion-transmission of Zika Virus. FDA guidance for industry, August 2016. https:// www.fda.gov/downloads/biologicsbloodvaccines/guidanceco mplianceregulatoryinformation/guidances/blood/ucm518213. pdf. Accessed 28 Aug 2016.

10. Anez G, Rios M. Dengue in the United States of America: a worsening scenario? Biomed Res Int. 2013;2013:678645.

11. Petersen LR, Epstein JS. Chikungunya virus: new risk to transfusion safety in the Americas. Transfusion. 2014;54:1911-5.

12. Stramer SL, Hollinger FB, Katz LM, Kleinman S, Metzel PS, Gregory KR, et al. Emerging infectious disease agents and their potential threat to transfusion safety. Transfusion. 2009;49(Suppl 2):1S-29S.

13. Stein E, Elbadawi LI, Kazmierczak J, Davis JP. Babesiosis surveillance-Wisconsin, 2001-2015. MMWR Morb Mortal Wkly Rep. 2017;66:687-91.

14. Stramer SL, Dodd RY, AABB Transfusion-Transmitted Diseases Emerging Infectious Diseases Subgroup. Transfusion-transmitted emerging infectious diseases: 30 years of challenges and progress. Transfusion. 2013;53(10 Pt 2):2375-83.

15. Jacobs MR, Good CE, Lazarus HM, Yomtovian RA. Relationship between bacterial load, species virulence, and transfusion reaction with transfusion of bacterially contaminated platelets. Clin Infect Dis. 2008;46(8): 1214-20.

16. Hong H, Xiao W, Lazarus HM, Good CE, Maitta RW, Jacobs MR. Detection of septic transfusion reactions to platelet transfusions by active and passive surveillance. Blood. 2016;127:496-502

17. Corean J, Al-Tigar R, Pysher T, Blaylock R, Metcalf RA. Quality improvement after multiple fatal transfusion-transmitted bacterial infections. Am J Clin Pathol. 2018;149(4):293-9.

18. Snyder EL, Stramer SL, Benjamin RJ. The safety of the blood supply: time to raise the bar. N Engl J Med. 2015;372:1882-5.
19. The INTERCEPT Blood System for Platelets Package Insert. Cerus Corporation; 2018. Available online at https://interceptusa.com/images/resources/Package_Inserts/INTERCEPT_ Blood_System_INT2530B_DS_Package_Insert_May-2018. pdf. Accessed 01 June 2018.

20. Standards for Blood Banks and Transfusion Services. 30th ed. AABB; 2016. Available at https://marketplace.aabb.org/ebusiness/ Default.aspx $?$ TabID $=251 \&$ productId $=12991997$. Accessed 27 Apr 2016.

21. Platelet PGD Test Package Insert. Verax Biomedical; P00583 Rev. $\mathrm{G}, 2015 / 06$.

22. Lyons NM, Prioli KM, Pizzi LT. Cost of platelet purchase and production: a survey of US Hospitals. Poster presentation at the 22nd annual international meeting of the international society for pharmacoeconomics and outcomes research; 20-24 May 2017: Boston, MA.

23. Bureau of Labor Statistics (BLS). May 2015 National Occupational Employment and Wage Estimates. Available at https://www. bls.gov/oes/2015/may/oessrcst.htm. Accessed 15 Nov 2016.

24. Employer costs for employee compensation. 2016. http://www. bls.gov/news.release/pdf/ecec.pdf. Accessed 15 Nov 2016.

25. Prioli KM, Pizzi LT, Karp JK, Galanis T, Herman JH. Plasma cost focus group. cost of purchased versus produced plasma from donor recruitment through transfusion. Appl Health Econ Health Policy. 2016;14(5):609-17.

26. National Blood Collection, Utilization, and Patient Blood Management Survey Report. AABB; 2013. Available at: http://www. aabb.org/research/hemovigilance/bloodsurvey/Documents/2013AABB-Blood-Survey-Report.pdf. Accessed 9 Jan 2017.

27. McCullough J, Goldfinger D, Gorlin J, Riley WJ, Sandhu H, Stowell C, et al. Cost implications of implementation of pathogeninactivated platelets. Transfusion. 2015;55(10):2312-20.

28. Kleinman S, Dumont LJ, Tomasulo P, Bianco C, Katz L, Benjamin RJ, et al. The impact of discontinuation of 7-day storage of apheresis platelets (PASSPORT) on recipient safety: an illustration of the need for proper risk assessments. Transfusion. 2009;49(5):903-12.

29. Girona-Llobera E, Jimenez-Marco T, Galmes-Trueba A, Muncunill J, Serret C, Serra N, et al. Reducing the financial impact of pathogen inactivation technology for platelet components: our experience. Transfusion. 2014;54(1):158-68.

30. Agency for Healthcare Research and Quality HCUPNet. Available at: http://hcupnet.ahrq.gov. Accessed 27 Nov 2016.

31. SwissMedic haemovigilance annual reports, 2010-2015. Available at https://www.swissmedic.ch/swissmedic/en/home/human arzneimittel/market-surveillance/haemovigilance/publicatio ns.html. Accessed 4 Jan 2017.

32. Rapports d'activité hémovigilance/Hemovigilance Activity Reports, 2006-2015. Agence nationale de sécurité du médicament et des produits de santé/French National Agency for Medicine and Health Product Safety. Available at: http://ansm.sante.fr/Media theque/Publications/Bilans-Rapports-d-activite-Bilans-et-rappo rts-d-activite\#folder_26762. Accessed 4 Jan 2017.

33. Benjamin RJ, Braschler T, Weingand T, Corash LM. Hemovigilance monitoring of platelet septic reactions with effective bacterial protection systems. Transfusion. 2017;57(12):2946-57.

34. Hospital outpatient prospective payment: notice of final rulemaking (NFRM) with comment period. https://www.cms.gov/Medic are/Medicare-Fee-for-Service-Payment/HospitalOutpatientPP S/Hospital-Outpatient-Regulations-and-Notices-Items/CMS1678-FC.html?DLPage $=1 \&$ DLEntries $=10 \& D L S o r t=2 \& D L S o r$ tDir=descending. Accessed 30 Nov 2017.

35. Dunbar NM, Dumont LJ, Szczepiorkowski ZM. How do we implement day 6 and day 7 platelets at a hospital-based transfusion service? Transfusion. 2016;56:1262-6. 
36. Larson R, Aronson CA. Enhanced platelet bacterial screening in an eight-hospital system. AP52. AABB annual meeting; Oct 2017: San Diego, CA.

37. Li JW, Brecher ME, Jacobson JL, Harm SK, Chen D, El-Gamil A, et al. Addressing the risk of bacterial contamination in platelets: a hospital economic perspective. Transfusion. 2017;57:2321-8.

38. Amato M, Schennach H, Astl M, Chen CY, Lin JS, Benjamin RJ, et al. Impact of platelet pathogen inactivation on blood component utilization and patient safety in a large Austrian Regional Medical Centre. Vox Sang. 2017;112(1):47-55.

39. Osselaer JC, Doyen C, Defoin L, Debry C, Goffaux M, Messe $\mathrm{N}$, et al. Universal adoption of pathogen inactivation of platelet components: impact on platelet and red blood cell component use. Transfusion. 2009;49:1412-22.

40. Mendez B, McCable E, DelMonte J, Becker JL. The effects of PAS and PR on platelet use. CP311. Poster presentation at AABB; Oct 2017: San Diego, CA.

41. Arefian H, Heublein S, Scherag A, Brunkhorst FM, Younis MZ, Moerer O, et al. Hospital-related cost of sepsis: a systematic review. J Infect. 2017;74:107-17.
42. Jones SL, Ashton CM, Kiehne LB, Nicolas JC, Rose AL, Shirkey $\mathrm{BA}$, et al. Outcomes and resource use of sepsis-associated stays by presence on admission, severity, and hospital type. Med Care. 2016;54(3):303-10.

43. Navy wife who lost kidneys after giving birth awarded $\$ 24.7 \mathrm{M}$. https://www.usnews.com/news/best-states/hawaii/articles/201803-08/navy-wife-who-lost-kidneys-after-giving-birth-awarded247m. Accessed 5 Mar 2018.

44. FDA Blood Products Advisory Committee 2017. Meeting materials. https://www.fda.gov/AdvisoryCommittees/CommitteesMeeti ngMaterials/BloodVaccinesandOtherBiologics/BloodProductsAd visoryCommittee/ucm543914.htm. Accessed 5 Mar 2018.

45. National Blood Collection and Utilization in the United States (NBCUS) report. Presented at the AABB annual meeting; 22-25 Oct 2016: Orlando, FL. 